\title{
Decision support and safety of clinical environments
}

\section{A H Morris}

Qual Saf Health Care 2002;11:69-75

Safety in the clinical environment is based on structures that reduce the probability of harm, on evidence that enhances the likelihood of actions that increase favourable outcomes, and on explicit directions that lead to decisions to implement the actions dictated by this evidence. A clinical decision error rate of only $1 \%$ threatens patient safety at a distressing frequency. Explicit computerised decision support tools standardise clinical decision making and lead different clinicians to the same set of diagnostic or therapeutic instructions. They have favourable impacts on patient outcome. Simple computerised algorithms that generate reminders, alerts, or other information, and protocols that incorporate more complex rules reduce the clinical decision error rate. Decision support tools are not new; it is the new attributes of explicit computerised decision support tools that deserve identification. When explicit computerised protocols are driven by patient data, the protocol output (instructions) is patient specific, thus preserving individualised treatment while standardising clinical decisions. The expected decrease in variation and increase in compliance with evidence-based recommendations should decrease the error rate and enhance patient safety.

Supported by the NIH (RO1-HL-36787, NO1-HR-46062), AHCPR (HS 06594), Deseret Foundation, Respiratory Distress Syndrome Foundation, LDS Hospital, and $\mathrm{IHC}$ Inc.

Correspondence to: $\mathrm{Dr} \mathrm{AH}$ Morris, Pulmonary Division, LDS Hospital, Salt Lake City, Utah 84143, USA; amorris@ihc.com

Accepted for publication 7 January 2002
S afety in the clinical environment is based on structures that reduce the probability of harm, on evidence that enhances the likelihood of actions that increase favourable outcomes, and on explicit directions that lead to decisions to implement the actions dictated by this evidence. Fundamental to all appropriate action are the skills of operators to execute the proper tasks correctly. The successful translation of evidence-based research results into clinical practice has the potential to reduce errors in healthcare delivery, both near misses and errors leading to injury (adverse events), ${ }^{12}$ including both execution (slips and lapses) and planning errors. ${ }^{3}$ Medicine is a domain "... in which there are available many more wrong responses than correct ones...". ${ }^{5}$ Left to our own devices, we clinical decision makers are too likely to make well intended but erroneous decisions. The healthcare delivery system has a well established need for innovative methods to translate research results and evidence-based guidelines into practice. The human behaviour modification required for some of these new methods is a barrier to implementation. Providers commonly fail to adopt and implement evidence-based interventions. For completeness, one must acknowledge that some error may enhance favourable patient outcomes. For example, an error in administration of agents to suppress premature ventricular contractions following myocardial infarction 15 years ago would have violated the consensus recommendations. Yet these recommendations were later proved to be incorrect and the omission error would have increased the patient's probability of survival. $^{6-8}$ Given the imperfect state of our clinical knowledge, we must remain alert to the need to formally and systematically test the effects of interventions intended to reduce error. Their impact on ultimate clinical outcomes should be an important determinant of their role in clinical practice.

Reason dictates that we reduce errors. However, human limitations guarantee that clinical error will not disappear. Human error and injury are unavoidable. ${ }^{349}{ }^{10}$ Clinical error rates are common (1-50\%). ${ }^{9-37}$ Most human errors are not as egregious as those that lead to the occasional wrong limb amputations so dramatically touted in the news and are therefore difficult to detect. Adverse drug events are generally undetected. Traditional screening for in-hospital adverse drug events detects only $1 \%$ and voluntary reporting only $12 \%$ of the adverse drug events detected by automated computerised screening of an integrated electronic clinical database. ${ }^{38}$ In addition, the impact of clinical error can be important, even when the error rate is as low as $1 \% .{ }^{36}$ Many, if not most, clinical errors result from system problems. Humans cannot be relied upon consistently to render decisions that comply with evidence-based recommendations.

Humans have limited ability to deal effectively with large amounts of information. A clinical decision error rate of only $1 \%$ in the intensive care unit (ICU) threatens patient safety at a distressing frequency. ${ }^{2736}$ This is probably also true of other, non-ICU, environments. This provides a benchmark for the standardisation of clinical decisions and the reduction of unnecessary variation in practice. The goal for standardisation should be an error rate of $<1 \%$ if we are to make important progress towards elimination of threats to patient safety. The impact of most efforts, including guidelines and education, falls far short of this goal. A systems approach to this problem has clear potential to ameliorate the current unacceptable clinical error rate. The use of computerised protocols at the point of care to establish an explicit method seems to be a reasonable means of iteratively improving treatment, of reducing error, and of increasing quality. $^{39-41}$ 


\section{IMPORTANCE OF EXPLICIT METHODS}

An explicit decision support tool standardises clinical decision making and leads different clinicians to the same set of diagnostic or therapeutic instructions. By standardising clinical decision making, it establishes an explicit clinical method and provides a basis for comparison with alternative clinical methods. In the parlance of the continuous quality improvement movement, an explicit method is part of the "stabilisation of process" necessary to improve quality ${ }^{42-45}$ Both paper based and computerised protocols can theoretically contain the detail necessary to include most clinical scenarios and patient data combinations. Clinicians draw inferences with paper based protocols. An inference engine (computer program) draws inferences with computerised protocols. In practice, the different methods of drawing inferences produce different levels of detail in the rule sets of the protocols. The computerised protocol contains much more detail than is humanly possible to expect in the paper based protocol. Clinicians must use their judgment to fill in the gaps in logic, even when the paper based protocol contains much detail. ${ }^{46}$ This fosters variation among clinical decision makers and unnecessary variation in clinical practice and research. It does not seem possible for humans, without the stimulus of computerisation, to include the detail necessary for explicit protocols for complex clinical problems.

Clinical care (the treatment a patient receives) is determined by both the clinical caregiver's decisions and by the patient's individualised response to the illness and interventions. ${ }^{39} 40$ Using explicit decision support tools to standardise the clinician's response to the patient's expressions of disease, we can approach more closely the patient's contribution to this patient-caregiver relationship. Variability in response among clinicians ${ }^{29}{ }^{47-52}$ is an important contributor to "noise" in the patient-caregiver system. ${ }^{28} 394053$ Decision support tools decrease clinician induced "noise" because they decrease unnecessary variation. An increase in the signal-tonoise ratio for clinical outcomes can follow and thus enhance our ability to recognise changes in clinical outcome. Unexpectedly, individualisation of patient treatment is preserved when clinical decisions are standardised with explicit detailed patient data driven computerised protocols. ${ }^{39}{ }^{40}$ This is one of the most attractive attributes of the point of care use of computerised protocols. An essential element in achieving this unexpected result is the use of patient data-that is, the patient's unique expression of the disease $\mathrm{e}^{54-61}$ - to drive the decision support tool (protocol) rules. In contrast, time driven decision support tools-for example, a clinical path that requires discharge of the patient after 3 days of care-raise legitimate concerns about patient invariant ("cookbook") care.

\section{EVIDENCE THAT DECISION SUPPORT TOOLS INCREASE SAFETY}

Control of the process of medical care is beneficial. ${ }^{62}{ }^{63}$ Decision support tools can be categorised as "reminders", "consultants", or as "educational" products. ${ }^{64}$ Many forms of guidelines, clinical paths, and protocols are available. They can support clinical decision making ${ }^{65}$ and influence clinician performance and patient outcome favourably. ${ }^{626-68}$ They can avoid vexing problems in different areas of clinical medicine $^{4769}$ and thus appear generally applicable. They respond to limitations of human decision making that are largely independent of the task. Benefit can therefore be expected in many healthcare domains.

Protocols with the greatest potential to standardise clinical decisions explicitly articulate the rules for selecting patients, for identifying patient states, or for generating specific instructions for treatment. Of these, explicit computerised protocols contain the greatest detail. They may achieve the upper limit of uniformity of clinical decision making, short of the application of the closed loop controllers ${ }^{70}$ that eliminate humans from the decision making process. Computer based clinical decision support systems have favourable impacts on patient outcome ${ }^{68}$ Simple computerised algorithms that generate reminders, alerts, or other information ${ }^{12} 58$ 71-73 and protocols that incorporate more complex rule based and extensive data based instructions ${ }^{59}{ }^{61}{ }^{74}$ reduce the clinical decision error rate. Paper based and computerised decision support tools that provide explicit point of care (point of decision making) instructions to clinicians have achieved clinician compliance rates of $90-95 \%$. $^{406} 61$

Evidence has long supported the conclusion that standardisation of clinical decision making with computerised protocols is desirable and productive in both clinical research and clinical care. Computerised protocols have favourable impacts on important clinical outcomes in hospital pharmacy and infectious disease departments ${ }^{58}{ }^{59} 75-77$ and in both outpatient and inpatient hospital practice. ${ }^{12} 3861717576$ 78-89 Computerised protocols have controlled the intensity of care of patients with acute respiratory distress syndrome in both treatment arms of a randomised clinical trial. ${ }^{55}$ Three benefits follow the use of such explicit computerised protocols: (1) precise description of the method (process) of patient care (the rules and logic for clinical decision making); (2) assurance of equal intensity of care (experimental group equation or equivalence ${ }^{5}$ ); and (3) achievement of common intermediate end points (for example, treatment regulated to produce the same $\mathrm{PaO}_{2}$ and $\mathrm{pH})$. While a large body of evidence underpins the use of explicit guidelines and their favourable impact on important clinical outcomes, these protocols have only controlled a small part of the unnecessary variation in critical care and even less in medical care in general. Only a small number of important non-experimental cointerventions-such as mechanical ventilation, antibiotic choices, intravenous fluid therapy, and haemodynamic support-have yet been systematically addressed with explicit decision support tools.

"Evidence has long supported the conclusion that standardisation of clinical decision making with computerised protocols is desirable and productive in both clinical research and clinical care"

Explicit decision support might also reduce safety, for several reasons. Firstly, guidelines (or more explicit detailed protocols) might induce harm if they were inflexible and failed to respond to patient differences. They would lead to "cookbook medicine" and, without proper clinical oversight, result in errors. They would probably not be appropriate for the management of more complex clinical issues. However, they can be used for simple tasks such as oxygen therapy following surgery with general anaesthesia or the use of penicillin or its equivalent for group A streptococcal pharyngitis in children. Secondly, clinical trainees might abandon critical thinking and guidelines might contribute to the production of clinicians less prepared for the rigorous intellectual challenge of healthcare delivery. However, a wisely used explicit method can be an effective teaching tool for both decision making and clinical practice. Explicit decision support tools articulate the variables considered and the decision rules, unlike much traditional clinical teaching. When training is valued, explicit methods can be an asset. When training is not valued they could be a disadvantage. Like any tool they can be misused. Thirdly, some fear that clinical innovation might be stifled, particularly if clinician reimbursement were linked to standard practice guidelines. Finally, many physicians are concerned that their role will be diminished and that they may become disenchanted with medicine if widespread mandatory guideline and protocol use is instituted. ${ }^{90}$ 
Table 1 Comparison of four tools (developed elsewhere) available for withdrawing mechanical ventilation from patients following cardiac surgery showing both the variability between decision support tools and the inexplicit nature of most of them

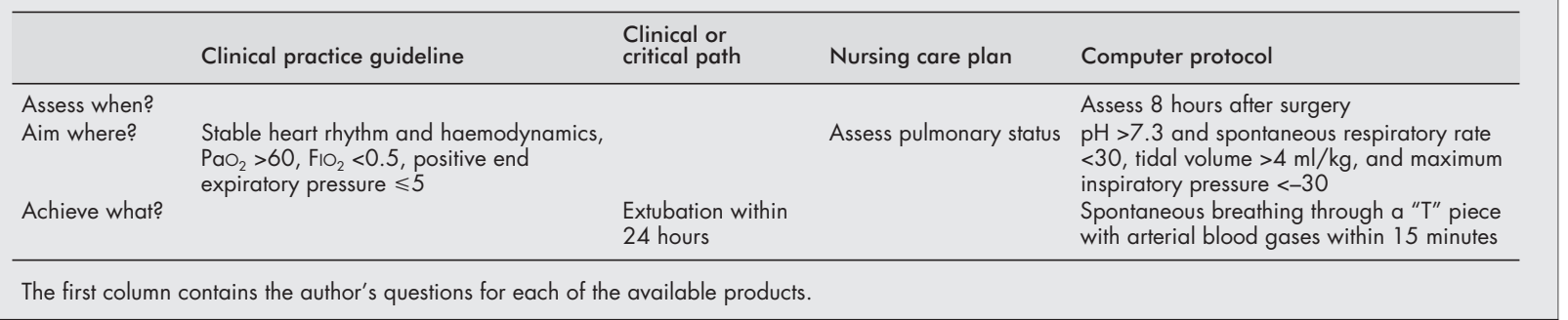

\section{ATTRIBUTES OF SUCCESSFUL GUIDELINES/ PROTOCOLS}

Thousands of decision support tools with different names, foci, and outputs are currently available to clinical practitioners. Many of these lack specific instructions for commonly encountered clinical practice scenarios and are useful only in a conceptual sense. ${ }^{80-95}$ They neither standardise clinical decisions nor lead to uniform implementation of clinical interventions, although that is their intended purpose (table 1). ${ }^{8895} 96$ Inexplicit guidelines that omit important details force the clinician to fill in the gaps in logic or identified variables. ${ }^{97-99}$ Judgment, background, and experience will vary among clinicians and so, therefore, will the choices of rules and variables they use to fill in the gaps of inexplicit guidelines and algorithms. In addition, a single clinician will probably fill in the logic gaps with different choices at different times, even though faced with the same clinical expression of the disease.

Clinicians and patients expect treatment to be tailored to the patient's specific needs. If decision support tools are perceived to be unable to accommodate relevant variations among patients, clinicians will reject them. It seems axiomatic to demand that clinicians respond to the patient's individualised expression of disease. The anticipated patient responses are major determinants of clinical decision making. However, this focus can be misleading. While the understanding of patient response is our goal, the important unit of analysis for advancement of our clinical knowledge is not the patient, but the combined patient-caregiver unit. ${ }^{39} 4055$ The patientcaregiver unit is one example of the holistic "transactional unit" articulated by Altman and colleagues. ${ }^{100} 101$ One cannot study patient response effectively in the absence of the clinician and the surrounding clinical environment, just as one cannot study the clinician's response in the absence of the patient.

\section{WHAT NEW ATTRIBUTES DO EXPLICIT COMPUTERISED DECISION SUPPORT TOOLS CONTRIBUTE?}

Decision support is a broadly applicable concept that embraces many activities in human life. Physicians have for years used tools brought to the point of care (point of decision making) as aids. These include a myriad of pocket editions of texts, antibiotic therapy guides, diagnostic algorithms, and treatment synopses. Decision support tools are therefore not new. It is the new attributes of explicit computerised decision support tools that deserve identification here. These include point of care application with stationary or hand-held devices, incorporation of enough detail to be explicit, capture and storage of patient data in an electronic format, identification of temporal changes, consistency, and reproducibility. When explicit computerised protocols are driven by patient data, the protocol output (instructions) is patient-specific, thus preserving individualised treatment while standardising clinical decisions. ${ }^{39} 40$ This is an important non-intuitive property that deserves emphasis among clinicians.

\section{WHY WOULD ONE EXPECT DECISION SUPPORT TOOLS TO IMPROVE PATIENT SAFETY?}

Clinical decision makers are faced with more variables than they can easily manage. ${ }^{1} 101826272971102103$ Our interpretation of physiological data is frequently inaccurate. ${ }^{49}$ Ill defined terms or statements-such as the advice from the Society of Critical Care Medicine that "... caution should be exercised when pulmonary artery occlusion pressure becomes increased to the extent that pulmonary edema is a risk" ${ }^{\prime 104}$ — contribute to variability and error. ${ }^{39} 4048$ Clinicians cannot reasonably be expected systematically to generate therapeutic decisions that are coherent, that consider all appropriate options, and that are consistent with the relevant scientific evidence. ${ }^{105}$

Compliance of physicians with evidence-based treatments or guidelines is low across a broad range of healthcare topics. $^{54} 60$ 106-114 The links between compliance, quality, error, and ultimate clinical outcome are complex and difficult to tease out of the literature. Physician compliance with quality indicators is higher than compliance with evidence-based practice guidelines, and reached $75 \%$ when using intense physician feedback with achievable benchmarks. ${ }^{115}$ However, this does not illuminate the issues that surround the standardisation of clinical decision making at the point of care. ${ }^{5661116}$ The goals of quality assessment and those of clinical care need not coincide. One must be circumspect when reviewing quality indicator reports if one's interest lies in clinical decision making. Computerised protocols for mechanical ventilation have been associated with clinician compliance of $94 \%$ in 11 different hospitals. ${ }^{40}{ }^{55}{ }^{61}$ Many factors, including cultural issues and health beliefs, influence compliance. ${ }^{117}{ }^{118}$ Widespread distribution of evidence-based guidelines ${ }^{119} 120$ and education programmes $^{121-125}$ have had only a limited impact on compliance.

\section{CULTURAL CONDITIONS THAT ENHANCE ADOPTION OF EXPLICIT DECISION SUPPORT TOOLS} One must incorporate cultural concerns to fully grasp the determinants of safe care. Humans resist the adoption of innovations when they threaten the status quo. Decades of persistent work by innovative thinkers have produced products that appear to provide satisfactory decision support in clinical practice but these have not been widely adopted. ${ }^{126-131}$ In fact, the healthcare profession may be unusually resistant to the adoptions of "disruptive innovations", innovations perceived to be a threat to the institutions and providers of current practice. ${ }^{132}$ The absence of requisite infrastructure in the clinical environment is an important obstacle to the adoption of clinical decision support tools. Computer systems require major investments. The unstable information technology business with its frequent takeovers and failures (such as Emtek $($ ) , Oasis $($ ) ) presents additional barriers to the practising community and its clinicians.

The cultural environment at LDS Hospital and Intermountain Health Care Inc has fostered progress in decision support development during the past 25 years. The LDS Hospital 
enjoys a striking tradition of collaboration and group development which may be a reflection of the attitudes of the majority Mormon culture. It set the stage for collaboration between front line clinicians, researchers, physicians, nurses, respiratory therapists, and administrators. The other central building block was the integrated electronic medical record (HELP system) established in about 1970 at LDS Hospital. ${ }^{133-137}$ We began in critical care in the 1970s with development of monitoring, data management and reporting, and reminder outputs from the integrated electronic HELP database. ${ }^{138}$ We then developed more complex outputs using logical arguments and data from multiple sources. One such example is the following alert (paraphrased) generated as part of a daily routine respiratory care quality assurance activity using data from the HELP database: "Patient \# \# in W820 grew Pseudomonas aeruginosa from a sputum culture. This organism was also recovered from patient \#\# in E630; respiratory therapist \#\# \# \# cared for both patients." ${ }^{138}$ We then developed complex protocols in paper and then computerised versions ${ }^{139}$ to meet a research need. ${ }^{55}$ The collaborative environment and our mutual commitment to the research question launched our work in decision support with the unexpected outcome that decision support appeared to be more important than the investigation for which it had been initially invoked..$^{39-41} 56$ 61 139-141 Our collaborations with decision support tools evolved into a broader interest in safety. We use protocols to reduce unnecessary variation, reduce error, and increase patient safety through systems approaches. ${ }^{142-145}$

\section{SYSTEM VERSUS INDIVIDUAL APPROACH}

Human error and injury have their roots in the organisation itself. $^{27}{ }^{146} 147$ The common focus on the individual clinician as the pertinent element of analysis ${ }^{27} 148149$ is at odds with multiple lines of reasoning and scholarship, including systems theory, ${ }^{150}$ scaling, ${ }^{150}{ }^{151}$ the understanding of emergent properties that appear with higher levels of integration, ${ }^{152}$ and the transactional world view of environmental psychology. ${ }^{100} 101$

Systems can be configured to support human decision makers. Systems configured with checks (for example, data consistency checks in industrial plants and internal consistency checks for clinical data such as systolic, diastolic and mean blood pressure, heart rate from ECG and pulse oximetry), reminders at the point of decision making (automobile seat belt warning lights), and automatic interlocks (automobile brake ignition interlocks) all reduce human error rates. Systems without these basic decision support tools have been associated with disaster-for example, the Chernobyl nuclear power plant meltdown.

The evidence that guidelines and explicit methods improve clinical outcomes and safety in healthcare delivery systems is compatible with results from systems approaches in other human activities. In the manufacturing sector an understanding of the performance of the system (stabilisation of process) is a prerequisite to quality improvement. ${ }^{42-45}{ }^{153}$ In the airline and aerospace industry, in the nuclear power and its regulatory industry, and in the military the adoption of systems approaches to error control and the use of root cause and accident precursor analyses are widespread and successful. Human behaviour in healthcare delivery is qualitatively similar to that in these other human activities. Experience in these other fields probably applies to health care. ${ }^{3454} 155$ Applications of root cause and accident precursor analyses in healthcare delivery systems appear promising.

\section{CONCLUSIONS}

Medicine, like social science, enjoys an "ecology of science ... in which there are available many more wrong responses than correct ones ...". ${ }^{5}$ Individualised decision making unsupported by outcome data is likely to be both variable and incorrect in complex clinical circumstances. Computerised protocols possess a unique potential for increasing the rigour of clinical care

\section{Key messages}

- Safety in the clinical environment is based on structures that reduce the probability of harm, on evidence that enhances the likelihood of actions that increase favourable outcomes, and on explicit directions that lead to decisions to implement the actions dictated by this evidence.

- Explicit computerised decision support tools standardise clinical decision making and lead different clinicians to the same set of diagnostic or therapeutic instructions.

- Simple computerised algorithms that generate reminders, alerts, or other information, and protocols that incorporate more complex rules reduce the clinical decision error rate.

- Decision support tools are not new; it is the new attributes of explicit computerised decision support tools that deserve identification.

- When explicit computerised protocols are driven by patient data, the protocol output (instructions) is patient specific, thus preserving individualised treatment while standardising clinical decisions.

- The expected decrease in variation and increase in compliance with evidence-based recommendations should decrease the error rate and enhance patient safety.

and of experimental clinical research by providing explicit methodology with the highest level of detail while preserving individualised (patient specific) treatment. The expected decrease in variation and increase in compliance with evidence-based recommendations should decrease error and enhance patient safety. Achievement of this end will require a culture that supports collaboration and consensus, one that fosters a synthesis of thought and consensus as a complement to the individual decision making freedom of the past.

\section{ACKNOWLEDGEMENTS}

The author is indebted to the medical, nursing, and respiratory therapy staffs of the Intermountain Respiratory Intensive Care Unit and of the Shock-Trauma/Intermountain Respiratory ICU and the Respiratory Care Department of the LDS Hospital for collaboration during the past 25 years. The author acknowledges the contributions of Drs James Orme Jr, Terry Clemmer, Lindell Weaver, Frank Thomas, Tom East, Jane Wallace, George Thomsen, James Pearl, Nat Dean, and Brad Rasmusson for their collaboration in protocol development and implementation; Drs Paul Barach, Steven Small, Brent James, Jonathan Nebeker, Charlene Weir, and Polly Wiessner for insights into errors in health care delivery; and Drs Roberta Goldring, Robert Rogers, and Waldemar Johanson who, through their vision and insight, have enabled the decision support effort for the past 16 years.

\section{REFERENCES}

1 Barach P, Small SD. Reporting and preventing medical mishaps: lessons from non-medical near miss reporting systems. BM 2000;320:759-63.

2 Berman S. The AMA clinical quality improvement forum on addressing patient safety. Jt Comm J Qual Improv 2000;26:428-33.

3 Reason J. Human error. Cambridge, UK: Cambridge University Press, 1990.

4 Reason J. Human error: models and management. BM 2000;320:768-70

5 Campbell D, Stanley J. Experimental and quasi-experimental designs for research (reprinted from Handbook of research on teaching, 1963). Boston: Houghton Mifflin Co, 1966

6 Cardiac Arrhythmia Suppression Trial (CAST) investigators Preliminary report: effect of encainide and flecainide on mortality in a randomized trial of arrhythmia suppression after myocardial infarction. N Engl J Med 1989;321:406-12.

7 Pratt C, Brater D, Harrell Jr F, et al. Clinical and regulatory implications of the cardiac arrhythmia suppression trial (editorial). Am J Cardiol 1990;65:103-5.

8 Greene $\mathbf{H}$, Roden D, Katz R, et al, CAST investigators. The cardiac arrythmia suppression trial: first CAST ... then CAST-II. J Am Coll Cardiol 1992;19:894-8.

9 Abramson NS, Wald KS, Grenvik ANA, et al. Adverse occurrences in intensive care units. JAMA 1980;244:1582-4.

10 Wu A, Folkman S, McPhee $S$, et al. Do house officers learn from their mistakes? JAMA 1991;265:2089-94. 
11 Williamson J, Goldschmidt P, Jillson I. Medical practice information demonstration project: final report. Contract \#282-77-0068GS Baltimore, MD: Office of the Assistant Secretary of Health, DHEW, 1979

12 McDonald CJ, Wilson GA, McCabe G Jr. Physician response to computer reminders. JAMA 1980;244:1579-81.

13 West J. An autopsy method for evaluating trauma care. J Trauma $1981 ; 21: 32-4$

14 Morris AH, Chapman RH, Gardner RM. Frequency of technical problems encountered in the measurement of pulmonary artery wedge pressure. Crit Care Med 1984;1 2:164-70.

15 Morris AH. Elimination of pulmonary wedge pressure errors commonly encountered in the ICU. Cardiologia (Italy) 1985;30:941-3.

16 Browner W, Newman T. The analogy between diagnostic tests and clinical research. JAMA 1987;257:2459-63.

17 Physicians ACo. Working conditions and supervision for residents in internal medicine programs: recommendations. Ann Intern Med 1989:1 10:657-63

18 Iberti T, Fischer E, Leibowitz $M$, et al. A multicenter study of physician's knowledge of the pulmonary artery catheter. JAMA 1990;264:2928-32.

19 Brook R. Using scientific information to improve quality of health care. In: Warren K, Mosteller F, eds. Doing more good than harm: the evaluation of health care interventions. New York: New York Academy of Sciences, 1993: 74-85.

20 Chalmers T, Lau J. Randomized controlled trials and meta-anlayses in gastroenterology: major achievements and future potential. In: Warren K, Mosteller F, eds. Doing more good than harm: the evaluation of health care interventions. New York: New York Academy of Sciences, 1993 96-106

21 Chan L, Schonfeld N. How much information is lost during processing: a case study of emergency department records. Comput Biomed Res 1993;26:582-9

$22 \mathrm{McNeil}$ B. Use of claims data to monitor patients over time: acute myocardial infarction as a case study. In: Warren K, Mosteller F, eds. Doing more good than harm: the evaluation of health care interventions. New York: New York Academy of Sciences, 1993: 63-73.

23 O'Connor G, Plume S, Wennberg J. Regional organization for outcomes research. In: Warren K, Mosteller F, eds. Doing more good than harm: the evaluation of health care interventions. New York: New York Academy of Sciences, 1993: 44-51.

24 Warren K, Mosteller F, eds. Doing more good than harm: the evaluation of health care interventions. New York: New York Academy of Sciences, 1993

25 Wennberg J, Barry M, Fowler F, et al. Outcomes research, PORTs, and health care reform. In: Warren K, Mosteller F, eds. Doing more good than harm: the evaluation of health care interventions. New York: New York Academy of Sciences, 1993: 52-62.

26 Iberti TJ, Daily EK, Leibowitz AB, et al. Assessment of critical care nurses' knowledge of the pulmonary artery catheter. Pulmonary Artery Catheter Study Group. Crit Care Med 1994;22:1674-8.

27 Leape L. Error in medicine. JAMA 1994;272:1851-7.

28 Tyson NdG. Signal versus noise. Natural History 1996;105:72-6.

29 Gnaegi A, Feihl F, Perret C. Intensive care physicians' insufficient knowledge of right-heart catheterization at the bedside: time to act?. Crit Care Med 1997;25:213-20.

30 Schulz E, Barrett J, Price C. Read code quality assurance: from simple syntax to semantic stability. J Am Med Inform Assoc 1998:5:337-46.

31 Sudeep N, Anuradha L, Obasanio O, et al. Errors in the treatment of tuberculosis in Baltimore. Chest 2000;1 17:734-7.

32 Palevsky PM, Bhagrath R, Greenberg A. Hypernatremia in hospitalized patients. Ann Intern Med 1996;1 24:197-203.

33 Kohn L, Corrigan J, Donaldson M, eds. To err is human: building a safer health system. Washington, DC: National Academy Press, 1999.

34 Nakhleh RE, Zarbo RJ. Amended reports in surgical pathology and implications for diagnostic error detection and avoidance: a College of American Pathologists Q-probes study of 1,667,547 accessioned cases in 359 laboratories. Arch Pathol Lab Med 1998;122:303-9.

35 Krizek TJ. Surgical error: ethical issues of adverse events. Arch Surg 2000:135: 1359-66

36 Gopher D, Olin M, Badihi Y, et al. The nature and causes of human errors in a medical intensive care unit. In: Proceedings of the human factors and ergonomics society annual meeting. 1989: 956-60.

37 Jones JK, Fife D, Curkendall S, et al. Co-prescribing and co-dispensing of cisapride and contraindicated drugs. JAMA 2001;286:1607-9.

38 Classen DC, Pestotnik SL, Evans RS, et al. Computerized surveillance of adverse drug events in hospital patients. JAMA 1991;266:2847-51.

39 Morris A. Algorithm-based decision making. In: Tobin M, ed. Principles and practice of intensive care monitoring. New York: McGraw-Hill, 1998: 1355-81

40 Morris A. Developing and implementing computerized protocols for standardization of clinical decisions. Ann Intern Med 2000;132:37383.

41 Morris A, Cook D. Clinical trial issues in mechanical ventilation. In: Marini J, Slutsky A, eds. Physiologic basis of ventilatory suport. New York: Marcel Dekker, 1998: 1359-98.

42 Deming W. Quality, productivity, and competitive position. Cambridge, Mass: Massachusetts Institute of Technology, Center for Advanced Engineering Study, 1982

43 Deming W. Out of the crisis. Cambridge, Mass: Massachusetts Institute of Technology, Center for Advanced Engineering Study, 1986.

44 Shewart W. Economic control of quality of manufactured product. New York: D Van Nostrand, 1931 (republished in 1980 by the American Society for Quality Control, 230 W. Wells St, Milwaukee, Wisconsin 53203).
45 Walton M. The Deming management method. New York: Putnam Publishing Group (Perigee books), 1986.

46 The Acute Respiratory Distress Syndrome Network. Ventilation with lower tidal volumes as compared with traditional tidal volumes for acute lung injury and the acute respiratory distress syndrome. N Engl J Med 2000;342:1301-8.

47 Leiner G, Abramowitz S, Small M. Pulmonary function testing in laboratories associated with residency training programs in pulmonary diseases. Am Rev Respir Dis 1969;100:240-4

48 Morris A. Hemodynamic guidelines. Crit Care Med 1993;21:1096 (see editorial by Gay PC. Of pundits, professors, and pollsters. Crit Care Med 1993;21:959-60)

49 Ontario Intensive Care Study Group. Evaluation of right heart catheterization in critically ill patients. Crit Care Med 1992;20:928-33.

50 Wennberg JE. Dealing with medical practice variations: a proposal for action. Health Aff 1984;3:6-32.

51 Wennberg JE. Variations in medical practice and hospital costs. Conn Med 1985;49:444-53.

52 Wennberg JE, Gittelsohn A. Small area variation analysis in health care delivery. Science 1973;142:1102-8.

53 Hulley S, Cummings S. Designing clinical research. Baltimore: Williams and Wilkins, 1988

54 Evans RS, Pestotnik SL, Classen DC, et al. A computer-assisted management program for antibiotics and other antiinfective agents. N Engl J Med 1998;338:232-8

55 Morris A, Wallace C, Menlove R, et al. Randomized clinical trial of pressure-controlled inverse ratio ventilation and extracorporeal $\mathrm{CO}_{2}$ removal for ARDS. Am J Respir Crit Care Med 1994;149:295-305 (erratum 1994;149:838; letters to the editor 1995;151:255-6, 1995;151:1269-70, and 1997;156:1016-7).

56 East TD, Böhm SH, Wallace CJ, et al. A successful computerized protocol for clinical management of pressure control inverse ratio ventilation in ARDS patients. Chest 1992;101:697-710.

57 East T. Role of the computer in the delivery of mechanical ventilation. In Tobin $M$, ed. Principles and practice of mechanical ventilation. New York: McGraw-Hill, 1994: 1005-38.

58 Classen DC, Evans RS, Pestotnik SL, et al. The timing of prophylactic administration of antibiotics and the risk of surgical wound infection. N Engl J Med 1992;326:281-6.

59 Pestotnik S, Classen D, Evans R, et al. Implementing antibiotic practice guidelines through computer-assisted decision support: clinical and financial outcomes. Ann Intern Med 1996;124:884-90.

60 Classen DC, Pestotnik SL, Evans RS, et al. Adverse drug events in hospitalized patients: exess length of stay, extra costs, and attributable mortality. JAMA 1997;277:301-6.

61 East T, Heermann L, Bradshaw R, et al. Efficacy of computerized decision support for mechanical ventilation: results of a prospective multi-center randomized trial. Proc AMIA Symp 1999: 251-5.

62 Wirtschafter DD, Scalise M, Henke C, et al. Do information systems improve the quality of clinical research? Results of a randomized trial in a cooperative multi-institutional cancer group. Comput Biomed Res $1981 ; 14: 78-90$

63 Dawes R, Faust D, Meehl P. Clinical versus actuarial judgement. Science 1989;243: 1668-74.

64 Miller R, Goodman K. Ethical challenges in the use of decision-support software in clinical practice. In: Goodman K, ed. Ethics, computing, and medicine: informatics and the transformation of health care. Cambridge, UK: Cambridge Univeristy Press. 1998: 102-15.

65 Grimshaw J, Russell I. Effect of clinical guidelines on medical practice: a systematic review of rigorous evaluations. Lancet 1993;342:1317-22.

66 Grimm RH, Shimoni K, Harlan WR, et al. Evaluation of patient-care protocol use by various providers. N Engl J Med 1975;292:507-1 1.

67 Safran C, Rind D, Davis R, et al. Effects of a knowledge-based electronic patient record on adherence to practice guidelines. MD Comput 1996:13:55-63.

68 Johnston $M$, Langton K, Haynes B, et al. Effects of computer-based clinical decision support systems on clinician performance and patient outcome. Ann Intern Med 1994;120:135-42.

69 Hirsh J. Oral anticoagulant drugs. N Engl J Med 1991;324:1865-75.

70 Blesser W. A systems approach to biomedicine. New York: McGraw-Hill, 1969.

71 McDonald CJ. Protocol-based computer reminders, the quality of care and the non-perfectability of man. N Engl J Med 1976;295:1351-5.

72 Dexter PR, Perkins S, Overhage JM, et al. A computerized reminder system to increase the use of preventive care for hospitalized patients. N Engl J Med 2001:345:965-70.

73 Kuperman GJ, Teich JM, Gandhi TK, et al. Patient safety and computerized medication ordering at Brigham and Women's Hospital. Jt Comm J Qual Improv 2001;27:509-21.

74 Morris A. Evaluating and refining a hemodynamic protocol for use in a multicenter ARDS clincial trial. Am J Respir Crit Care Med 2000; 161 (Suppl 3):A378

75 Evans RS, Burke JP, Pestotnik SL, et al. Prediction of hospital infections and selection of antibiotics using an automated hospital database. In: Proceedings of 14th Annual Symposium on Computer Applications in Medical Care, Baltimore, MD. Los Alamitos, CA: IEEE Computer Soc Press, 1990: 663-7

76 Evans RS, Pestotnik SL, Burke JP, et al. Reducing the duration of prophylactic antibiotics use through computer monitoring of surgical patients. Ann Pharmacother 1990;24:351-4.

77 Evans R, Classen D, Pestotnik S, et al. A decision support tool for antibiotic therapy. In: Safran C, ed. Proceedings of 19th Annual 
Symposium on Computer Applications in Medical Care (SCAMC), New Orleans. New York: McGraw-Hill, 1995: 651-5.

$78 \mathrm{McDonald}$ CJ. Use of a computer to detect and respond to clinical events: its effect on clinician behavior. Ann Intern Med 1976;84:162-7.

79 Tierney W, McDonald C, Martin D, et al. Computerized display of past test results. Ann Intern Med 1987:107:569-74.

80 McDonald C, Tierney W. Computer-stored medical records: their future role in medical practice. JAMA 1988;259:3433-40

81 Tierney W, McDonald C, Hui S, et al. Computer predictions of abnormal test results: effects on outpatient testing. JAMA 1988;259:1 194-8.

82 Tierney W, Miller M, McDonald C. The effect on test ordering of informing physicians of the charges for outpatient diagnostic tests. N Engl J Med 1990;322:1499-504.

83 Tierney W, Miller M, Overhage J, et al. Physician inpatient order writing on microcomputer work stations. JAMA 1993;269:379-83.

84 Pestotnik SL, Evans RS, Burke JP, et al. Development of a computerized infectious disease monitor (CIDM). Comput Biomed Res 1990;18:103-13.

85 Evans RS, Burke JP, Classen DC, et al. Computerized identification of patients at high risk of hospital-acquired infection. Am J Infect Control 1992;20:4-10.

86 Classen DC, Pestotnik SL, Evans RS, et al. Intensive surveillance of midazolam use in hospitalized patients and the occurrence of cardiordespiratory arrest. Pharmacotherapy 1992;12:213-6.

87 Evans R, Pestotnik S, Classen D, et al. Prevention of adverse drug events through computerized surveillance. In: Proceedings of 16th Annual Symposium on Computer Applications in Medical Care, Baltimore, MD. Los Alamitos, CA: IEEE Computer Soc Press, 1992: 437-41.

88 Tierney WM, Overhage JM, Takesue BY, et al. Computerizing guidelines to improve care and patient outcomes: the example of heart failure. J Am Med Inform Assoc 1995:2:316-22.

89 McDonald CJ. Medical heuristics: the silent adjudicators of clinical practice. Ann Intern Med 1996;124:56-62.

90 Tierney WM, Overhage JM, McDonald CJ. Computerizing guidelines: factors for success. In: Cimino J, ed. Proceedings of 1996 AMIA Annual Fall Symposium (formerly SCAMC). Washington: Hanley \& Belfus, 1996: 459-62.

91 Audet A-M, Greenfield S, Field M. Medical practice guidelines: current activities and future directions. Ann Intern Med 1990;1 13:709-14

92 Fletcher R, Fletcher S. Clinical practice guidelines. Ann Intern Med 1990;113:645-6.

93 Hadorn D, McCormick K, Diokno A. An annotated algorithm approach to clinical guideline development. JAMA 1992;267:331 1-4.

94 Miller P, Frawly S. Trade-offs in producing patient-specific recommendations from a computer-based clinical guideline: a case study. J Am Med Inform Assoc 1995;2:238-42.

95 Fridsma D, Gennari J, Musen M. Making generic guidelines site-specific. In: Cimino J, ed. Proceedings of 1996 AMIA Annual Fall Symposium (formerly SCAMC). Washington: Hanley \& Belfus, 1996: 597-601.

96 Field $M$, Lohr K, eds. Clinical practice guidelines: directions for a new program (summary). Washington: National Academy Press, 1990.

97 Armstrong R, Bullen C, Cohen S, et al. Critical care algorithms. New York: Oxford University Press, 1991.

98 Don $\mathrm{H}$, ed. Decision making in critical care. Philadelphia: B C Decker Inc, 1985

99 Karlinsky J, Lau J, Goldstein R. Decision making in pulmonary medicine Philadelphia: B C Decker, 1991.

100 Altman I, Rogoff B. World views in psychology: trait, interactional, organismic, and transactional perspectives. In: Stokols D, Altman I, eds. Handbook of environmental psychology. New York: John Wiley \& Sons, 1987: 7-40.

101 Werner C, Brown B, Altman I. Planning and doing transactionally-oriented research: Examples and strategies. In: Stokols D, Altman I, eds. Handbook of environmental psychology II. New York: John Wiley \& Sons, 2002 (in press).

102 Tversky A, Kahneman D. Availability: a heuristic for judging frequency and probability. In: Kahneman D, Slovic P, Tversky A, eds. Judgment under uncertainty: heuristics and biases. Cambridge, UK: Cambridge University Press, 1982: 163-78

103 Jennings D, Amabile T, Ross L. Informal covariation assessment: data-based versus theory-based judgments. In: Kahneman D, Slovic P, Tversky A, eds. Judgment under uncertainty: heuristics and biases. Cambridge, UK: Cambridge University Press, 1982: 211-30.

104 Guidelines Committee, Society of Critical Care Medicine. Guidelines for the care of patients with hemodynamic instability associated with sepsis. Crit Care Med 1992;20:1057-9.

105 Pocock SJ. Clinical trials: a practical approach. New York: John Wiley \& Sons, 1983

106 Nelson E, Splaine M, Batalden P, et al. Building measurement and data collection into medical practice. Ann Intern Med 1998:128:460-6.

107 Schacker T, Collier AC, Hughes J, et al. Clinical and epidemiologic features of primary HIV infection. Ann Intern Med 1996;125:257-64 (erratum 1997;126:174)

108 Kiernan M, King AC, Kraemer HC, et al. Characteristics of successful and unsuccessful dieters: an application of signal detection methodology. Ann Behav Med 1998;20: 1-6.

109 Galuska DA, Will JC, Serdula MK, et al. Are health care professionals advising obese patients to lose weight? JAMA 1999;282:1576-8.

110 Dickerson JE, Hingorani AD, Ashby M, et al. Optimisation of antihypertensive treatment by crossover rotation of four major classes. Lancet 1999;353:2008-13.
111 Avorn J. Putting adverse drug events into perspective. JAMA 1997;277:341-2

112 Bates D, Spell, N, Cullen D, et al. The costs of adverse drug events in hospitalized patients. JAMA 1997:277:307-11.

113 Lesar T, Briceland L, Stein D. Factors related to error in medication prescribing. JAMA 1997;277:312-7.

114 Johnson J, Bootman J. Drug-related morbidity and mortality; a cost of illness model. Arch Intern Med 1995;155:1949-56.

115 Kiefe Cl, Allison JJ, Williams OD, et al. Improving quality improvement using achievable benchmarks for physician feedback: a randomized controlled trial. JAMA 2001;285:2871-9.

116 Henderson S, Crapo R, Wallace C, et al. Performance of computerized protocols for the management of arterial oxygenation in an intensive care unit. Int J Clin Monit Comput 1992;8:271-80.

117 Cochrane G. Compliance in asthma. Eur Respir Rev 1998;8:239-42.

118 Jones P. Health status, quality of life and compliance. Eur Respir Rev 1998:8:243-6

119 Lomas J, Anderson GM, Domnick-Pierre K, et al. Do practice guidelines guide practice? The effect of a consensus statement on the practice of physicians. N Engl J Med 1989;321:1306-1 1.

120 Greco P, Eisenberg J. Changing physicians' practices. N Engl J Med 1993;329:1271-4.

121 Singer $M$, Haft R, Barlam T, et al. Vancomycin control measures at a tertiary-care hospital: impact of interventions on volume and patterns of use. Infect Control Hosp Epidemiol 1998:19:248-53.

122 Pritchard RS, Fisher ES, Teno JM, et al. Influence of patient preferences and local health system characteristics on the place of death. Study to Understand Prognoses and Preferences for Risks and Outcomes of Treatment (SUPPORT) Investigators. J Am Geriatr Soc 1998;46:124250.

123 Teno J, Lynn J, Connors AFJ, et al. The illusion of end-of-life resource savings with advance directives. Study to Understand Prognoses and Preferences for Risks and Outcomes of Treatment (SUPPORT) Investigators. J Am Geriatr Soc 1997;45:513-8.

124 Teno JM, Licks S, Lynn J, et al. Do advance directives provide instructions that direct care? Study to Understand Prognoses and Preferences for Risks and Outcomes of Treatment (SUPPORT) Investigators. J Am Geriatr Soc 1997:45:508-12.

125 Lo B. Improving care near the end of life: why is it so hard? JAMA 1995;274:1634-6.

126 Weed L. Physicians of the future. N Engl J Med 1981;304:903-7.

127 Weed L. New connections between medical knowledge and patient care. BM 1997;315:231-5.

128 Weed L. Reengineering medicine: questions and answers. Fed Bull $1995 ; 82: 24-36$

129 Weed L. Reengineering medicine. Fed Bull 1994;81:149-83.

130 Burgher $\mathrm{C}$. The use of problem knowledge couplers in a primary care practice. Healthe Inform Manage 1997;11:13-26.

131 Weed L, Weed L. Opening the black box of clinical judgment. BM (eBM edition) 1999;319:1-32, 1-11, 1-1 1, 1-12, 1-8.

132 Christensen C, Bohmer B, Kenagy J. Will disruptive innovations cure health care? Harvard Business Rev 2000; 78: 102-12.

133 Warner H, Olmsted C, Rutherford B. HELP: a program for medical decision-making. Comput Biomed Res 1972;5:65-74.

134 Hulse R, Clark S, Jackson J, et al. Computerized medication monitoring system. Am J Hosp Pharm 1976;33:1061-4.

135 Gardner RM, West BJ, Pryor TA, et al. Computer-based ICU dato acquisition as an aid to clinical decision-making. Crit Care Med 1982; 10:823-30

136 Pryor TA. The HELP medical record system. MD Computing $1988 ; 5: 22-33$

137 Kuperman GJ, Garder RM, Pryor TA. HELP: a dynamic hospital information system. New York: Springer-Verlag, 1991.

138 Morris AH, Gardner RM. Computer applications. In: Hall J, Schmidt G, Wood L, eds. Principles of critical care. New York: McGraw-Hill, 1992: 500-14.

139 East T, Morris A, Gardner R. Computerized management of mechanical ventilation. In: Grenvik A, Ayres S, eds. Textbook of critical care. 3rd ed. Philadelphia: W B Saunders, 1995: 895-911

140 Morris A. Protocol management of ARDS. New Horizons 1993;1:593-602.

141 Morris A. Rational use of computerized protocols in the ICU. Crit Care $2001 ; 5: 249-54$

142 Clemmer TP, Spuhler VJ, Berwick DM, et al. Cooperation: the foundation of improvement. Ann Intern Med 1998;128:1004-9.

143 Clemmer TP, Spuhler VJ, Oniki TA, et al. Results of a collaborative quality improvement program on outcomes and costs in a tertiary critical care unit. Crit Care Med 1999:27:1768-74.

144 Oniki TA, Clemmer TP, Arthur LK, et al. Using statistical quality contro techniques to monitor blood glucose levels. Proc Annu Symp Comput Appl Med Care 1995:586-90.

145 Clemmer TP. Nutrition support teams: role in the new health care environment. Nutr Clin Pract 1994;9:217-20.

146 Staender S, Davies J, Helmreich B, et al. The anaesthesia critical incident reporting system: an experience based database. Int J Med Inf 1997; $47: 87-90$ 
147 Galletly DC, Mushet NN. Anaesthesia system errors. Anaesth Intensive Care 1991;19:66-73.

148 Joint Commission on Accreditation of Healthcare Organizations. What every hospital should know about sentinel events. Oakbrook

Terrace, IL: Joint Commission on Accreditation of Healthcare Organizations, 2000

149 Joint Commission on Accreditation of Healthcare Organizations. Root cause analysis in health care: tools and techniques. Oakbrook Terrace, IL: Joint Commission on Accreditation of Healthcare Organizations, 2000

150 Miller J. Living systems. New York: McGraw-Hill, 1978.
151 Mandelbrot B. The fractal geometry of nature. New York: W H Freeman, 1983

152 Schultz S. Homeostasis, humpty dumpty, and integrative biology. News Physiol Sci 1006;11:238-46.

153 Imai M. Kaizen: the key to Japan's competitive success. New York: McGraw-Hill, 1986.

154 Prochaska JO, DiClemente CC, Norcross JC. In search of how people change. Applications to addictive behaviors. Am Psychol 1992;47: 1 102-14.

155 Rogers EM. Diffusion of innovations. 4th ed. New York: Free Press, 1995. 